\title{
The impact of beliefs about mental health problems and coping on outcome in schizophrenia
}

\author{
F. LOBBAN*, C. BARROWCLOUGH AND S. JONES \\ University of Liverpool, UK; University of Manchester, UK
}

\begin{abstract}
Background. Using the theoretical framework of the Self Regulation Model (SRM), many studies have demonstrated that beliefs individuals hold about their physical health problems are important in predicting health outcomes. This study tested the SRM in the context of a mental health problem, schizophrenia.
\end{abstract}

Method. One hundred and twenty-four people with a diagnosis of schizophrenia were assessed on measures of symptom severity, beliefs about their mental health problems, coping and appraisal of outcome at two time points, 6 months apart.

Results. Using multivariate analyses and controlling for severity of symptoms, beliefs about mental health were found to be significant predictors of outcome. Beliefs about greater negative consequences were the strongest and most consistent predictors of a poorer outcome in both crosssectional and longitudinal analyses.

Conclusions. These results suggest that the SRM is a promising model for mental health problems and may highlight important areas for development in clinical, and especially psychosocial interventions.

\section{INTRODUCTION}

In physical health research many social cognition models have been proposed to identify key beliefs mediating the impact of disease factors on emotional and behavioural responses (Connor \& Norman, 1995). Overall, these models have shown that beliefs about illness account for significant variance in outcome appraisal and are amenable to change. These findings offer important opportunities for clinical interventions.

The Self Regulation Model (SRM; Leventhal et al. 1984) assumes that people are problem solvers whose health-related behaviours are attempts to close the perceived gap between their current health and their future goal state. The model proposes that coping strategies are guided

* Address for correspondence: Dr F. Lobban, Department of Clinical Psychology, The Whelan Building, The Quad, Brownlow Hill, The University of Liverpool, Liverpool, L69 3GB, UK.

(Email: fiona.lobban@liverpool.ac.uk) by interpretation of illness experiences. Individuals constantly appraise their outcome in relation to their desired health state and modify their beliefs and behaviour accordingly.

The SRM hypothesizes that beliefs about identity, cause, consequences, timeline and the potential for control/cure are the key beliefs guiding responses. These beliefs can be assessed using the Illness Perception Questionnaire (IPQ; Weinman et al. 1996). The recent Illness Perception Questionnaire Revised (IPQR; MossMorris et al. 2001), includes additional subscales: 'timeline cyclical' (how variable the symptoms are) and 'coherence' (how much individuals believe they understand their illness). The control dimension has been divided into personal and treatment control, and a dimension to assess the 'emotional' response of the individual has been added. IPQR is explicitly designed to be modified to suit particular illnesses and for research use. 
Outcome appraisal is defined as perceptions of current health state and has been assessed in various ways, the most common focusing on the individuals' perceived quality of life, emotional state or current level of functioning. These foci recognize the broad impact of physical health problems. In studies into schizophrenia, the main outcome is often symptom severity but this may not always be the most desirable outcome from the patients' perspective. A more psychological perspective, in which the ultimate aim is to reduce distress, suggests that emotional state, quality of life, satisfaction and functioning are important outcome variables; therefore these are used as measures of outcome appraisal in this study. Recent work by Birchwood et al. $(1993,2000)$ suggests that for some people with schizophrenia, an increase in emotional distress occurs after the remission of psychotic symptoms, and can be predicted by negative appraisals of this experience. Therefore, at least some variance in distress is associated with appraisals of psychosis rather than directly due to the psychotic process. This study attempts to examine appraisals about psychosis more closely.

\section{METHOD}

\section{Participants}

Participants were identified via Community Mental Health Teams. Diagnosis was taken from a systematic chart review using a checklist of diagnostic criteria based on DSM-IV (APA, 1994). Information about prescribed medication, length of contact with services and recent history of symptom fluctuations was taken from hospital notes.

\section{Measures}

All assessments were conducted by the first author (F.L.) or a research assistant.

\section{Symptom severity}

The Positive and Negative Syndrome Scale (PANSS; Kay et al. 1989) is widely used as a measure of symptom severity in schizophrenia and has acceptable levels of reliability and validity (Kay et al. 1989). A total of the positive and negative subscale scores was used in this study. The general subscale was not used as it has been shown to be less reliable (Purnine et al.
2000) and includes items that are confounded with appraisal of outcome (e.g. anxiety and depression). Each interviewer's reliability was assessed by comparing ratings of 10 interviews with those of an experienced consultant psychiatrist. Intra-class correlations suggested good inter-rater reliability $(0 \cdot 83-0 \cdot 95)$.

\section{Coping}

Coping was assessed using a structured interview in conjunction with the PANSS. For each item identified as a problem by the rater (a score of $4+$ on the PANSS), participants were asked about their primary appraisal of the experience, i.e. whether or not they perceived this to be a problem. If they did, they were asked to describe what coping strategies they used. Positive and negative strategies were defined by the taxonomy reported by Tarrier (1987) and Tarrier et al. (1993). Classifications were made by the first author (F.L.) and a Professor of Psychology (C.H.) that were highly reliable with each other $($ kappa $=0.88)$, and participants were categorized into the following variables for use in the analysis.

(1) Positive coping. $1=$ participant did not perceive any problems; $2=$ problems were perceived but a low frequency of positive strategies were reported (mean of less than two per problem); $3=$ problems were perceived and a high frequency of positive strategies were reported (mean of two or more per problem).

(2) Negative coping. $1=$ participant did not perceive any problems; $2=$ problems were perceived but no negative strategies reported; $3=$ problems were perceived and negative strategies used.

\section{Beliefs about mental health problems}

The Illness Perception Questionnaire for Schizophrenia (IPQS)

A modified version of the IPQR was used to assess beliefs about mental health problems. Adaptations were based on extensive qualitative interviews with people diagnosed with schizophrenia (Lobban \& Barrowclough, unpublished observations). Alphas for the subscales ranged from 0.68 to 0.87 , and all showed good testretest reliability (range $=0.57-0.95)$ (Lobban et al. in press). The subscales are summarized below and the items are listed in the Appendix. 
(1) Identity (58 items). Fifty-eight mental health experiences associated with schizophrenia were listed including positive symptoms, negative symptoms, affective symptoms, and side effects of medication. For each item participants were asked to indicate whether or not they had experienced this, and whether they attributed it to a mental health problem, effects of medication, and/or other factors. The remaining subscales all consisted of statements that were scored between 1 (=strongly disagree) and 5 (=strongly agree).

(2) Timeline acute/chronic (6 items).

(3) Timeline cyclical (4).

(4) Consequences (11).

(5) Personal control (4).

(6) Treatment control (5).

(7) Coherence (5).

High scores denote a more chronic and cyclical timeline, greater perceived negative consequences, greater perceived personal control and belief in treatment, and a sense of having a less coherent understanding. Although a causal subscale is included in the IPQS, the items were not easily classified into meaningful dimensions and are therefore not reported.

\section{Outcome measures}

(1) Hospital Anxiety and Depression Scale (HADS; Zigmund \& Snaith, 1983) consists of 14 items (7 for anxiety, 7 for depression), all of which are scored 0-3.

(2) The Manchester Short Assessment of Quality of Life (Priebe et al. 1999) is a condensed and slightly modified version of the Lancashire Quality of Life Profile (Oliver et al. 1991). Two scores were used: mean quality of life (QL) and satisfaction with mental health $(\mathrm{SMH})$, each rated on an 8-point scale.

(3) Global Assessment of Functioning (GAF; APA, 1994) is a measure of overall psychological disturbance rated by the interviewer. Only the GAF disability score was used in the main analysis. Reliability of the interviewers was assessed using a sub-sample of 10 participants who were rated by all three raters. The intraclass correlation $r=0.74 \quad(p<0.01)$, suggested adequate inter-rater reliability.

\section{Statistical analysis}

Not all participants completed all items. Therefore, the exact $n$ for each of the statistical tests is reported. Descriptive statistics are presented for all measures followed by univariate associations between beliefs, coping and outcomes. Multiple regression analyses were then used to identify which of the independent variables were the best predictors of the outcome variables both cross-sectionally at each time point and longitudinally. Only variables that were univariately associated with each outcome variable $(p<0.05)$ at either time point were included in the regression. Patient characteristics were entered into the first block using forward selection. Symptom severity was forced into the second block to ensure that this was always controlled for. Beliefs about mental health problems were entered into block three using forward selection. Finally coping strategies were entered into block four using forward selection. The categorical coping variables were coded as two dummy variables, the first indicating whether or not a problem was perceived (primary appraisal) and the second indicating whether or not a particular coping style was used.

Despite multiple testing, a statistical significance level of $p<0.05$ was chosen for interpreting the results. Given the exploratory nature of the study, the risk of making a type II error was considered more detrimental to future research than a type I error.

\section{RESULTS}

\section{Patient characteristics}

A total of 175 people were identified as eligible and invited into the study. Fifty-one declined, leaving a total sample size of 124 (response rate $=71 \%$ ). Participants were interviewed at two time points approximately 6 months apart ( mean $=197.59$ days, s.D. $=77.95$ days). Twentytwo people $(17 \cdot 7 \%)$ declined to be interviewed at time 2 . They did not differ significantly from those who were retained on any of the variables. A total of $94 \%$ of the sample $(n=116)$ had a diagnosis of schizophrenia $(n=105)$, or schizoaffective disorder $(n=11)$. The rest had a diagnosis of psychosis $(n=5)$, paranoid psychosis $(n=2)$ or delusional disorder $(n=1)$. The mean age of the sample was $38 \cdot 81$ years (s.D. $=10 \cdot 44$ years). The average length of contact with mental health services was 12.05 years (s.D. $=$ 8.65 years). A total of $32 \%(n=40)$ of the sample were receiving regular depot medication and 
Table 1. Mean scores on beliefs about mental health problems, and comparison across coping styles at time 1 and time 2 [ $F$ values ( $p$ value)]

\begin{tabular}{|c|c|c|c|c|c|c|}
\hline \multirow[b]{2}{*}{ IPQS subscale ( $n$ in each analysis) } & \multicolumn{3}{|c|}{ Time 1} & \multicolumn{3}{|c|}{ Time 2} \\
\hline & $\begin{array}{l}\text { Mean per item } \\
\text { (s.D.) }\end{array}$ & $\begin{array}{c}\text { Positive } \\
\text { coping } \\
\text { (ANOVA) }\end{array}$ & $\begin{array}{c}\text { Negative } \\
\text { coping } \\
\text { (ANOVA) }\end{array}$ & $\begin{array}{l}\text { Mean per item } \\
\text { (s.D.) }\end{array}$ & $\begin{array}{c}\text { Positive } \\
\text { coping } \\
\text { (ANOVA) }\end{array}$ & $\begin{array}{c}\text { Negative } \\
\text { coping } \\
\text { (ANOVA) }\end{array}$ \\
\hline Identity 58 items; mean total $(n=113)$ & $35 \cdot 10(11 \cdot 7)$ & $10 \cdot 74 * * *$ & $14 \cdot 39 * * *$ & $36 \cdot 56(12 \cdot 54)$ & $1 \cdot 52$ & $1 \cdot 91$ \\
\hline Proportion attributed to mental health $(n=113)$ & 0.63 & $0 \cdot 73$ & 1.09 & $0.64(0.28)$ & $0 \cdot 05$ & $0 \cdot 34$ \\
\hline Proportion attributed to medication $(n=113)$ & $0 \cdot 14$ & $0 \cdot 21$ & $0 \cdot 11$ & $0 \cdot 154(0 \cdot 15)$ & $0 \cdot 85$ & $0 \cdot 85$ \\
\hline Proportion attributed to other factors $(n=113)$ & $0 \cdot 31$ & $0 \cdot 45$ & $0 \cdot 50$ & $0.29(0 \cdot 27)$ & $0 \cdot 28$ & $1 \cdot 37$ \\
\hline Timeline acute/chronic $(n=109)$ & $3 \cdot 53(0 \cdot 76)$ & $4 \cdot 74 *$ & $4 \cdot 69^{*}$ & $3 \cdot 49(0 \cdot 76)$ & $1 \cdot 37$ & $1 \cdot 45$ \\
\hline Timeline cyclical $(n=111)$ & $3 \cdot 77(0 \cdot 65)$ & $7 \cdot 43 * *$ & $5 \cdot 88^{* *}$ & $3.79(0.67)$ & $0 \cdot 61$ & $1 \cdot 56$ \\
\hline Consequences $(n=111)$ & $3 \cdot 43(0 \cdot 58)$ & $2 \cdot 40$ & $3 \cdot 40^{*}$ & $3 \cdot 44(0 \cdot 60)$ & $1 \cdot 01$ & $0 \cdot 62$ \\
\hline Personal control $(n=109)$ & $3 \cdot 48(0 \cdot 70)$ & $13 \cdot 00 * * *$ & $16 \cdot 12 * * *$ & $3 \cdot 48(0 \cdot 66)$ & $0 \cdot 79$ & $2 \cdot 15$ \\
\hline Treatment control $(n=111)$ & $3 \cdot 53(0 \cdot 64)$ & $7 \cdot 95 * *$ & $2 \cdot 63$ & $3 \cdot 55(0 \cdot 65)$ & $0 \cdot 88$ & $0 \cdot 02$ \\
\hline Coherence $(n=112)$ & $2 \cdot 70(0 \cdot 69)$ & $3 \cdot 41^{*}$ & $1 \cdot 56$ & $2 \cdot 65(0 \cdot 70)$ & $0 \cdot 23$ & $1 \cdot 78$ \\
\hline
\end{tabular}

IPQS, the Illness Perception Questionnaire for Schizophrenia.

Significance levels: * $p<0 \cdot 05 ;{ }^{* *} p<0 \cdot 01$; *** $p<0 \cdot 001$.

$78 \%(n=97)$ were receiving oral antipsychotic medication (most commonly atypicals). All psychotic symptoms had been stable for at least 6 weeks. The mean premorbid IQ assessed using the National Adult Reading Test was 97 $($ S.D. $=16)$.

\section{Symptom severity}

The mean score on the PANSS positive subscale was $15 \cdot 12$ (S.D. $=5 \cdot 07$ ) and on the negative subscale was $13 \cdot 12($ S.D. $=4 \cdot 82)$. There was no significant difference between the PANSS score at time 1 and time $2(t=1 \cdot 454, \mathrm{df}=101, p=0 \cdot 149)$.

\section{Beliefs about mental health problems}

Table 1 shows mean scores per item on the IPQS. People reported experiencing well over half the symptoms listed. The majority of these were attributed to a mental health problem. People generally viewed their problems as chronic, cyclical and having high negative consequences. They felt they had some personal control over their symptoms and that treatment could offer some control. In general, people felt they had a coherent understanding of their mental health problems. There were no significant differences between scores at time 1 and time 2 on any IPQS subscales.

\section{Coping strategies}

Forty-two per cent of participants' primary appraisal was of not having any problems $(n=50)$ at time 1 and they were categorized into group 1 .
Of the remaining 74 people, 36 (29\% of the total sample) reported a high frequency of positive coping strategies and $21(17 \%)$ used negative coping strategies.

At time 2, there was an increase in the proportion of people who did not perceive any problems.

\section{Outcome measures}

The mean score on HADS anxiety was $9 \cdot 22$ $($ s.D. $=4 \cdot 50)$. The mean depression score was $7 \cdot 86$ (S.D. $=4 \cdot 34)$.

The mean overall quality of life rating was $4 \cdot 36$ (S.D. $=0 \cdot 85$ ), which reflects 'neither satisfied nor dissatisfied'. Satisfaction with mental health had a mean score of 3.63 (s.D. $=1.54)$, suggesting that overall the sample were less satisfied with their mental health than with other aspects of their lives.

The mean score on the GAF disability subscale was 48.28 (S.D. $=11 \cdot 30)$. This is consistent with 'serious impairment in social, occupational, or school functioning'.

There were no significant differences between scores at time 1 and time 2 on any of these measures.

\section{Univariate analyses}

Beliefs about mental health problems and coping strategies

Table 1 shows the results of ANOVAs to compare the three groups of people using different coping styles on each of the belief dimensions 
Table 2. Associations between independent variables (patient characteristics, symptom severity, beliefs, and coping) and dependent variables (outcome appraisal measures) at time $1(n=109-124)$

\begin{tabular}{|c|c|c|c|c|c|}
\hline Independent variables & HADS anxiety & HADS depression & QL & $\mathrm{SMH}$ & GAF disability \\
\hline Age & $0 \cdot 02$ & $0 \cdot 13$ & $-0 \cdot 14$ & $-0 \cdot 11$ & $-0 \cdot 17$ \\
\hline Sex ( $t$ value) & $-0 \cdot 44$ & $0 \cdot 05$ & -1.79 & $-0 \cdot 23$ & $-1 \cdot 87$ \\
\hline Length of contact with services & 0.08 & -0.03 & $-0 \cdot 05$ & -0.09 & -0.09 \\
\hline PANSS pos + neg & $0 \cdot 34 * *$ & $0 \cdot 27 * *$ & $-0 \cdot 42 * *$ & $-0 \cdot 32^{* *}$ & $-0 \cdot 46^{* *}$ \\
\hline Identity & $0 \cdot 36^{* *}$ & $0 \cdot 27 * *$ & $-0 \cdot 29 * *$ & $-0 \cdot 28 * *$ & $-0 \cdot 20^{*}$ \\
\hline Attributed to mental health problems & $0 \cdot 19^{*}$ & 0.09 & $-0 \cdot 10$ & $-0 \cdot 18$ & -0.09 \\
\hline Attributed to medication side effects & $-0 \cdot 09$ & $-0 \cdot 13$ & $0 \cdot 06$ & $0 \cdot 11$ & $0 \cdot 19 *$ \\
\hline Attributed to other factors & $-0 \cdot 18$ & -0.06 & $0 \cdot 04$ & $0 \cdot 21^{*}$ & $-0 \cdot 06$ \\
\hline Timeline acute/chronic & $0 \cdot 31^{* *}$ & $0 \cdot 28 * *$ & $-0 \cdot 24 *$ & $-0 \cdot 30 * *$ & $-0 \cdot 27 * *$ \\
\hline Timeline cyclical (non-parametric) & $0 \cdot 372^{* *}$ & $0 \cdot 452 * *$ & $-0 \cdot 263^{* *}$ & $-0 \cdot 190^{*}$ & $-0 \cdot 155$ \\
\hline Consequences & $0 \cdot 47 * *$ & $0 \cdot 54 * *$ & $-0 \cdot 61 * *$ & $-0 \cdot 48^{* *}$ & $-0 \cdot 41 * *$ \\
\hline Personal control & $-0 \cdot 17$ & $-0 \cdot 14$ & $0 \cdot 26^{* *}$ & $0 \cdot 30 * *$ & $0 \cdot 30 * *$ \\
\hline Treatment control (non-parametric) & $-0 \cdot 23^{*}$ & $-0 \cdot 26^{* *}$ & $0 \cdot 32 * *$ & $0 \cdot 35^{* *}$ & $0 \cdot 28 * *$ \\
\hline Coherence & $0 \cdot 13$ & $0 \cdot 32 * *$ & $-0 \cdot 22 *$ & $-0 \cdot 23^{*}$ & $-0 \cdot 20^{*}$ \\
\hline Positive coping strategies ( $F$ value) & $16 \cdot 42 * *$ & $7 \cdot 84 * *$ & $29 \cdot 01 * *$ & $21 \cdot 15^{* *}$ & $16 \cdot 25 * *$ \\
\hline Negative coping strategies ( $F$ value) & $16 \cdot 70^{* *}$ & $10 \cdot 86^{* *}$ & $32 \cdot 35^{* *}$ & $21 \cdot 48 * *$ & $21 \cdot 66 * *$ \\
\hline
\end{tabular}

GAF, Global Assessment of Functioning; HADS, the Hospital Anxiety and Depression Scale; QL, quality of life; SMH, satisfaction with mental health.

Significance levels: $* p<0 \cdot 05 ; * * \quad p<0 \cdot 01$

All values are Pearson's correlations except for variables labeled (non-parametric) where Spearman's correlations are shown, and for coping variables where the $F$ value for one-way ANOVA is given.

at time 1 and time 2. Significant differences at $p<0 \cdot 05$ were further explored using Gabriel's post-hoc tests to control for unequal group sizes.

Positive coping strategies. At time 1 participants whose primary appraisal was of not having any problems (group 1) reported fewer symptoms, a more acute and less cyclical timeline, greater belief in treatment to control symptoms, and a more coherent understanding of their mental health problems than at least one of the other two groups. Among those who did perceive a problem, high frequency of positive coping strategies (group 3) was associated with an increased perception of personal control than those who reported few positive coping strategies (group 2, $p=0.002$ ). At time 2 there were no significant differences between any of the groups.

Negative coping strategies. At time 1 participants whose primary appraisal was of not perceiving any problems (group 1) had the most acute and least cyclical timelines for their symptoms, and believed that they had greater control over their symptoms. There were no significant differences between the groups distinguished by their use of negative coping styles on these subscales. Use of negative coping strategies was positively associated with increased identity scores $(p=0.028)$, and more negative consequences $(p=0 \cdot 044)$. At time 2 there were no significant differences between any of the groups.

\section{Associations between independent variables and outcome measures}

Univariate relationships between the independent variables (patient characteristics, symptom severity, beliefs and coping) and dependent variables (outcome appraisal measures) are shown in Tables 2 and 3. None of the patient characteristics was directly associated with the outcome appraisal measures at time 1 , but at time 2 being female was associated with a higher GAF score. Symptom severity was associated with poorer outcome appraisal on all measures at both time points. All belief dimensions were associated with at least one of the outcome appraisal measures. Poorer outcome appraisal was consistently associated with a stronger identity, a more chronic and more cyclical timeline, greater perceived negative consequences, less control and less sense of a coherent understanding of mental health problems at both time points.

Outcomes also significantly differed between groups on the coping variables at time 1. Most of these differences were between groups who differed in their primary appraisal. However, people who did perceive a problem and who also 
Table 3. Associations between independent variables (patient characteristics, symptom severity, beliefs, and coping) and dependent variables (outcome appraisal measures) at time $2(n=84-102)$

\begin{tabular}{|c|c|c|c|c|c|}
\hline Independent variables & HADS anxiety & HADS depression & QL & SMH & GAF \\
\hline Age & $-0 \cdot 05$ & $0 \cdot 19$ & $-0 \cdot 14$ & $-0 \cdot 11$ & $-0 \cdot 07$ \\
\hline $\operatorname{Sex}(t$ value $)$ & -0.58 & $1 \cdot 67$ & $-0 \cdot 96$ & -0.93 & $-2 \cdot 07 *$ \\
\hline Length of contact with services & $0 \cdot 01$ & $-0 \cdot 04$ & $-0 \cdot 01$ & $-0 \cdot 07$ & $-0 \cdot 03$ \\
\hline PANSS pos + neg & $0 \cdot 32 * *$ & $0 \cdot 29 * *$ & $-0 \cdot 32 * *$ & $-0 \cdot 40 * *$ & $-0 \cdot 43^{* *}$ \\
\hline Identity & $-0 \cdot 05$ & $0 \cdot 36^{* *}$ & $-0 \cdot 34 * *$ & $-0 \cdot 30 * *$ & $-0 \cdot 22$ \\
\hline Attributed to mental health problems & $0 \cdot 22^{*}$ & $0 \cdot 16$ & $-0 \cdot 14$ & $-0 \cdot 19$ & $0 \cdot 06$ \\
\hline Attributed to medication side effects & $-0 \cdot 05$ & $-0 \cdot 14$ & $0 \cdot 26^{*}$ & $0 \cdot 14$ & $0 \cdot 11$ \\
\hline Attributed to other factors & $-0 \cdot 13$ & $-0 \cdot 15$ & $0 \cdot 03$ & $0 \cdot 15$ & $-0 \cdot 08$ \\
\hline Timeline acute/chronic & $0 \cdot 35^{* *}$ & $0 \cdot 44 * *$ & $-0 \cdot 13$ & $-0 \cdot 36^{* *}$ & $-0 \cdot 23^{*}$ \\
\hline Timeline cyclical (non-parametric) & $0 \cdot 45^{* *}$ & $0 \cdot 25^{*}$ & $-0 \cdot 18$ & $-0 \cdot 30 * *$ & $-0 \cdot 20$ \\
\hline Consequences & $0 \cdot 52^{* *}$ & $0 \cdot 58 * *$ & $-0 \cdot 54 * *$ & $-0 \cdot 53 * *$ & $-0 \cdot 34 * *$ \\
\hline Personal control & $0 \cdot 15$ & $-0 \cdot 21^{*}$ & $0 \cdot 14$ & $0 \cdot 27 *$ & $0 \cdot 18$ \\
\hline Treatment control & $-0 \cdot 47 * *$ & $-0 \cdot 34 * *$ & $0 \cdot 453^{* *}$ & $0 \cdot 34 * *$ & $0 \cdot 24 *$ \\
\hline Coherence & $0 \cdot 18$ & $0 \cdot 37 * *$ & $-0 \cdot 23^{*}$ & $-0 \cdot 24^{*}$ & $-0 \cdot 14$ \\
\hline Positive coping strategies ( $F$ value) & $4 \cdot 32^{*}$ & $0 \cdot 38$ & $2 \cdot 03$ & $4 \cdot 15 *$ & $4 \cdot 17 *$ \\
\hline Negative coping strategies ( $F$ value $)$ & $7 \cdot 48^{* *}$ & $0 \cdot 69$ & 1.59 & $5 \cdot 00 * *$ & $4 \cdot 27^{*}$ \\
\hline
\end{tabular}

GAF, Global Assessment of Functioning; HADS, the Hospital Anxiety and Depression Scale; QL, quality of life; SMH, satisfaction with mental health.

Significance levels: $* p<0 \cdot 05 ; * * p<0 \cdot 01$.

All values are Pearson's correlations except for variables labelled (non-parametric), where Spearman's correlations are shown, and for coping variables where the $F$ value for one-way ANOVA is given.

used negative strategies had poorer perceived quality of life $(p=0.032)$ and were rated as less able on the GAF $(p=0.013)$ than those who perceived a problem but did not use negative strategies.

All of the significant differences at time 2 were due to differences between those who perceived a problem and those who did not rather than differences in use of specific coping strategies.

\section{Multivariate analysis}

Table 4 shows the results of the regression analyses with the outcome appraisal measures as the dependent variables at time 1. All the analyses were repeated on the data collected at time 2 to test the reliability of the findings and the results are described in the text below. Longitudinal analyses were also performed in which time 1 independent variables were used to predict outcome scores at time 2 (see Table 5). Scores on the outcome appraisal measures at time 1 were controlled for by entering them into an additional first block in the regression analysis.

To check how well the regression equations fitted the data, the standardized residuals were checked. None had an absolute value greater than three, suggesting adequate fit of the data (Field, 2000).

\section{HADS anxiety}

Symptoms alone were able to account for $11.3 \%$ of the variance in anxiety at time 1 . With the addition of beliefs about symptoms, this increased to $34.2 \%$. High negative consequences, strong identity and lack of faith in the ability of treatment approaches to control symptoms were all associated with higher anxiety, though treatment control became non-significant in the final model. The addition of coping failed to account for any additional variance.

Cross-sectional analysis of data collected at time 2 showed consistent findings over time. The total adjusted $R^{2}$ was $43 \cdot 5 \%$. Direct significant predictors were consequences [standardized beta $(\mathrm{s} \beta)=0 \cdot 303]$, identity $(\mathrm{s} \beta=0 \cdot 290)$, and treatment control ( $\mathrm{s} \beta=-0 \cdot 307)$. Symptom severity just failed to reach significance $(p=0 \cdot 061)$. Coping failed to account for any additional variance at time 2.

The longitudinal analysis showed that the only significant predictor of anxiety at time 2 was anxiety at time 1 . This accounted for $46 \cdot 1 \%$ of the variance.

\section{HADS depression}

Severity of symptoms explained $7 \cdot 6 \%$ of the variance in depression at time 1 . With the addition of beliefs about mental health problems, 
Table 4. Multiple regressions with outcome appraisal measures as dependent variables. Cross-sectional analysis at time 1

\begin{tabular}{|c|c|c|c|c|c|c|}
\hline Outcome variable & $\begin{array}{l}\text { Independent variables in } \\
\text { the equation }\end{array}$ & Beta $(\beta)$ & CI Beta & $\mathrm{s} \beta$ & Sig. $(p=$ or $<)$ & $\begin{array}{c}\text { Adj. } R^{2} \text { with } \\
\text { variable added }\end{array}$ \\
\hline \multirow{5}{*}{ HADS anxiety $(n=109)$} & PANSS pos + neg & $0 \cdot 086$ & $0 \cdot 001$ to 0.173 & $0 \cdot 163$ & $0 \cdot 048$ & $0 \cdot 113$ \\
\hline & Consequences & $0 \cdot 175$ & 0.039 to 0.311 & $0 \cdot 237$ & $0 \cdot 012$ & $0 \cdot 280$ \\
\hline & Identity & 0.085 & $0 \cdot 013$ to $0 \cdot 157$ & $0 \cdot 205$ & $0 \cdot 021$ & $0 \cdot 318$ \\
\hline & Treatment control & $-0 \cdot 209$ & -0.448 to 0.030 & $-0 \cdot 141$ & $0 \cdot 086$ & $0 \cdot 342$ \\
\hline & Emotion focused coping & $2 \cdot 465$ & 0.732 to 4.197 & $0 \cdot 246$ & $0 \cdot 006$ & $0 \cdot 385$ \\
\hline \multirow[t]{3}{*}{ HADS depression $(n=111)$} & PANSS pos + neg & $0 \cdot 055$ & $-0 \cdot 037$ & $0 \cdot 100$ & $0 \cdot 240$ & $0 \cdot 076$ \\
\hline & Consequences & $0 \cdot 345$ & $0 \cdot 220$ & 0.469 & $0 \cdot 001$ & $0 \cdot 316$ \\
\hline & Coherence & $0 \cdot 305$ & 0.083 & $0 \cdot 224$ & $0 \cdot 008$ & $0 \cdot 357$ \\
\hline \multirow[t]{4}{*}{$\mathrm{QL}(n=108)$} & PANSS pos + neg & $-0 \cdot 019$ & -0.034 to -0.004 & $-0 \cdot 186$ & $0 \cdot 013$ & $0 \cdot 238$ \\
\hline & Consequences & $-0 \cdot 059$ & -0.079 to -0.040 & $-0 \cdot 434$ & $0 \cdot 001$ & $0 \cdot 491$ \\
\hline & Personal control & 0.046 & 0.005 to 0.086 & $0 \cdot 147$ & $0 \cdot 028$ & $0 \cdot 515$ \\
\hline & Primary appraisal & $-0 \cdot 552$ & -0.828 to -0.276 & $-0 \cdot 306$ & $0 \cdot 001$ & $0 \cdot 578$ \\
\hline \multirow[t]{6}{*}{ SMH $(n=108)$} & PANSS pos + neg & $-0 \cdot 022$ & -0.047 to $0 \cdot 014$ & $-0 \cdot 088$ & $0 \cdot 289$ & $0 \cdot 144$ \\
\hline & Consequences & $-0 \cdot 061$ & $-0 \cdot 103$ to $-0 \cdot 019$ & $-0 \cdot 245$ & $0 \cdot 005$ & $0 \cdot 291$ \\
\hline & Personal control & 0.076 & $-0 \cdot 016$ to $0 \cdot 1269$ & $0 \cdot 136$ & $0 \cdot 104$ & $0 \cdot 342$ \\
\hline & $\begin{array}{l}\text { Proportion of symptoms } \\
\text { attributed to other factors }\end{array}$ & $1 \cdot 419$ & $0 \cdot 397$ to $-2 \cdot 381$ & $0 \cdot 214$ & $0 \cdot 010$ & $0 \cdot 364$ \\
\hline & Treatment control & 0.096 & $0 \cdot 010$ to $0 \cdot 182$ & $0 \cdot 192$ & $0 \cdot 029$ & $0 \cdot 384$ \\
\hline & Primary appraisal & $-1 \cdot 154$ & -1.715 to -0.594 & $-0 \cdot 353$ & $0 \cdot 001$ & $0 \cdot 470$ \\
\hline \multirow{5}{*}{$\operatorname{GAF}(n=107)$} & PANSS pos + neg & $-0 \cdot 376$ & -0.619 to -0.133 & $-0 \cdot 269$ & $0 \cdot 003$ & $0 \cdot 217$ \\
\hline & Consequences & $-0 \cdot 335$ & -0.655 to -0.015 & $-0 \cdot 181$ & $0 \cdot 041$ & $0 \cdot 281$ \\
\hline & Personal control & $0 \cdot 640$ & -0.025 to -1.305 & $0 \cdot 153$ & $0 \cdot 059$ & $0 \cdot 317$ \\
\hline & $\begin{array}{l}\text { Proportion of symptoms attributed } \\
\text { to medication effects }\end{array}$ & $16 \cdot 137$ & $2 \cdot 780$ to $29 \cdot 494$ & $0 \cdot 187$ & $0 \cdot 018$ & $0 \cdot 342$ \\
\hline & Primary appraisal & $-6 \cdot 780$ & $-11 \cdot 161$ to $-2 \cdot 40$ & $-0 \cdot 280$ & $0 \cdot 003$ & $0 \cdot 393$ \\
\hline
\end{tabular}

GAF, Global Assessment of Functioning; HADS, the Hospital Anxiety and Depression Scale; PANSS, the Positive and Negative Syndrome Scale; QL, quality of life; SMH, satisfaction with mental health.

$\mathrm{s} \beta$, Standardized beta.

Table 5. Multiple regressions with outcome appraisal measures as dependent variables. Longitudinal analysis

\begin{tabular}{|c|c|c|c|c|c|c|}
\hline Outcome variable & $\begin{array}{c}\text { Independent variables in } \\
\text { the equation }\end{array}$ & $\operatorname{Beta}(\beta)$ & CI Beta & $\mathrm{s} \beta$ & Sig. $(p=$ or $<)$ & $\begin{array}{l}\text { Adj. } R^{2} \text { with } \\
\text { variable added }\end{array}$ \\
\hline HADS anxiety $(n=102)$ & HADS anxiety time 1 & 0.635 & 0.465 to 0.804 & 0.672 & $0 \cdot 001$ & $0 \cdot 461$ \\
\hline HADS depression $(n=91)$ & $\begin{array}{l}\text { HAD depression time } 1 \\
\text { PANSS pos }+ \text { neg time } 1 \\
\text { Consequences time } 1\end{array}$ & $\begin{array}{r}0 \cdot 552 \\
-0 \cdot 028 \\
0 \cdot 149\end{array}$ & $\begin{array}{r}0.376 \text { to } 0.729 \\
-0 \cdot 117 \text { to } 0 \cdot 061 \\
0.019 \text { to } 0 \cdot 278\end{array}$ & $\begin{array}{r}0.593 \\
-0.051 \\
0 \cdot 218\end{array}$ & $\begin{array}{l}0 \cdot 001 \\
0 \cdot 534 \\
0 \cdot 025\end{array}$ & $\begin{array}{l}0 \cdot 489 \\
0 \cdot 483 \\
0 \cdot 509\end{array}$ \\
\hline QL $(n=89)$ & $\begin{array}{l}\text { Quality of life time } 1 \\
\text { PANSS pos }+ \text { neg } \\
\text { Consequences time } 1 \\
\text { Negative coping strategies }\end{array}$ & $\begin{aligned} & 0 \cdot 399 \\
- & 0 \cdot 0007 \\
- & 0 \cdot 049 \\
- & 0 \cdot 407\end{aligned}$ & $\begin{array}{c}0.181 \text { to } 0.618 \\
-0.018 \text { to } 0.019 \\
-0.075 \text { to }-0.023 \\
-0.047 \text { to }-0.433\end{array}$ & $\begin{array}{r}0 \cdot 394 \\
0 \cdot 006 \\
-0 \cdot 361 \\
-0 \cdot 177\end{array}$ & $\begin{array}{l}0 \cdot 001 \\
0 \cdot 894 \\
0 \cdot 001 \\
0 \cdot 027\end{array}$ & $\begin{array}{l}0 \cdot 480 \\
0 \cdot 474 \\
0 \cdot 550 \\
0 \cdot 572\end{array}$ \\
\hline SMH $(n=91)$ & $\begin{array}{l}\text { SMH time } 1 \\
\text { PANSS pos }+ \text { neg time } 1 \\
\text { Consequences time } 1\end{array}$ & $\begin{array}{r}0 \cdot 371 \\
0 \cdot 032 \\
-0 \cdot 081\end{array}$ & $\begin{array}{c}0.144 \text { to } 0.598 \\
-0 \cdot 070 \text { to } 0.007 \\
-0.134 \text { to }-0.028\end{array}$ & $\begin{array}{r}0 \cdot 351 \\
-0 \cdot 152 \\
-0 \cdot 315\end{array}$ & $\begin{array}{l}0 \cdot 002 \\
0 \cdot 104 \\
0 \cdot 003\end{array}$ & $\begin{array}{l}0 \cdot 347 \\
0 \cdot 365 \\
0 \cdot 425\end{array}$ \\
\hline GAF disability $(n=96)$ & GAF disability time 1 & $0 \cdot 795$ & 0.670 to 0.921 & $0 \cdot 833$ & $0 \cdot 001$ & 0.689 \\
\hline
\end{tabular}

GAF, Global Assessment of Functioning; HADS, the Hospital Anxiety and Depression Scale; PANSS, the Positive and Negative Syndrome Scale; QL, quality of life; SMH, satisfaction with mental health.

$\mathrm{s} \beta$, Standardized beta.

symptom level was no longer a significant predictor and the amount of variance explained increased to $35.7 \%$. A perception of high negative consequences and lack of coherence were both associated with greater depression. Coping did not account for any additional variance.

Cross-sectional analysis of the time 2 data showed that, as at time 1, high negative 
consequences $(\mathrm{s} \beta=0 \cdot 381)$ and low coherence ( $\mathrm{s} \beta=0.333)$ were the strongest predictors of depression. Greater symptom severity $(\mathrm{s} \beta=0 \cdot 177)$ and a more chronic perception of timeline $(\mathrm{s} \beta=$ 0.279 ) were also direct predictors of greater depression at time 2. Coping did not account for any additional variance.

In the longitudinal analysis time 1 depression scores accounted for $48.9 \%$ of the variance in depression scores at time 2. High negative consequences at time 1 also significantly predicted later depression.

\section{$Q L$}

Lower symptom severity score was associated with higher QL and accounted for approximately $23.8 \%$ of the variance at time 1 . With the addition of beliefs about symptoms, the amount of variance accounted for increased to $51 \cdot 5 \%$. Perception of low negative consequences and greater personal control predicted higher perceived QL scores. Primary appraisal of not having a problem increased the amount of variance explained a small but significant amount to $57 \cdot 8 \%$.

The data at time 2 confirmed low negative consequences as the main predictor of high $\mathrm{QL}$ ( $\mathrm{s} \beta=-0 \cdot 555)$. Control was important again, though high treatment control $(\mathrm{s} \beta=0.289)$ was a stronger predictor of QL than personal control at time 2. Neither coping nor symptom severity were significant direct predictors of QL at time 2 .

In the longitudinal analysis quality of life at time 2 was strongly predicted by quality of life at time 1 . However, perceived negative consequences was also significant and increased the amount of variance accounted for from $48.0 \%$ to $55.0 \%$. Negative coping was able to account for a small but significant additional $2 \cdot 2 \%$ of variance.

\section{Satisfaction with mental health (SMH)}

Symptom severity was not a direct significant predictor of SMH at time 1. Perception of low negative consequences, greater treatment control and attributing a higher proportion of symptoms to factors other than mental health problems or medication effects was associated with increased SMH problems. These beliefs were able to account for $38.4 \%$ of the variance.
Primary appraisal increased this to $47 \%$. People who did not perceive themselves as having any problems reported higher satisfaction with their mental health.

Time 2 analysis supported the important role of beliefs about consequences in accounting for the greatest amount of variance in SMH. However, symptom severity was a direct predictor at time $2(\mathrm{~s} \beta=-0 \cdot 232)$. Symptoms accounted for approximately $11.5 \%$ of the variance in satisfaction, and beliefs about consequences ( $\mathrm{s} \beta=-0.496)$ increased this to $33.9 \%$. Primary appraisal and coping variables were unable to account for any additional variance.

$\mathrm{SMH}$ at time 1 positively predicted satisfaction at time 2 and accounted for approximately $34.7 \%$ of the variance. Higher perceived negative consequences at time 1 significantly predicted lower satisfaction at time 2 accounting for an additional $7 \cdot 8 \%$ of variance. Symptom severity was not a significant predictor.

\section{GAF-disability}

Symptom severity accounted for $21.7 \%$ of the variance in GAF scores with fewer symptoms being associated with higher GAF ratings. Beliefs about mental health problems increased this to $34 \cdot 2 \%$ with fewer perceived negative consequences, and attributing a higher proportion of symptoms to medication effects both being associated with higher GAF ratings. Primary appraisal increased the amount of variance accounted for to $39 \cdot 3 \%$. People who did not perceive themselves as having any problem received higher GAF ratings.

Very similar results were found using the time 2 data. Higher functioning was associated with lower symptom severity ( $\mathrm{s} \beta=-0 \cdot 368)$, and fewer negative consequences $(\mathrm{s} \beta=-0 \cdot 305)$. GAF scores were also higher for females than for males $(\mathrm{s} \beta=0 \cdot 205)$. Symptom severity accounted for approximately $17 \%$ of the variance and negative consequences increased this to $35 \cdot 3 \%$. None of the coping variables accounted for any additional variance.

There was very little change in GAF scores between time 1 and time 2 . GAF ratings at time 1 accounted for $68.9 \%$ of the variance in GAF ratings at time 2. None of the other variables accounted for any additional variance. 


\section{DISCUSSION}

The main findings from the study support the SRM in showing that variation in beliefs about mental health problems is associated with significant variation in appraisal of outcome both cross-sectionally and longitudinally.

In the cross-sectional analysis the amount of variation accounted for by beliefs in anxiety $(22.9 \%$ at time $1-26.8 \%$ at time 2$)$ and in depression $(28 \cdot 1 \%$ at time $1-41.5 \%$ at time 2$)$ is directly comparable to that found in physical health studies using similar methodologies (Rutter \& Rutter, 2000; Edwards et al. 2001; Fortune et al. 2002). In all of these studies beliefs about negative consequences were most strongly associated with outcome. Coherence was also an important predictor of depression in this study but was not assessed in the physical health studies. Perceived QL and SMH have also been used as measures of outcome appraisal in physical health. Rutter \& Rutter (2002) showed that for patients with IBS $26 \%$ of variance in perceived QL (compared to $27 \cdot 7-38.6 \%$ in this study) and $28 \%$ of variance in satisfaction with mental health (compared to $24 \cdot 0-22 \cdot 4 \%$ in this study) could be accounted for by illness beliefs with high negative consequences again showing the strongest relationship.

The GAF has not been used in previous studies but was included here as a non selfreport measure in order to test whether relationships between beliefs and outcome appraisal were largely a function of them being from a common source. The results from the GAF show that beliefs accounted for significant amounts of variance at both time points. As with the above analyses, perceived negative consequences were the strongest predictors of GAF ratings.

In this study we attempted to examine how beliefs at one time point could be used to predict outcome appraisal at a second time point. However, there was very little change over the 6-month period in either beliefs about mental health problems or outcome appraisal. Despite this, perception of greater negative consequences at time 1 did predict greater depression, lower perceived quality of life, and less satisfaction with mental health at time 2 . The amounts of variance accounted for by beliefs were small (2\% for depression, $7 \%$ for QL and 6\% for
$\mathrm{SMH}$ ) but comparable to those reported in longitudinal studies in physical health (e.g. Scharloo et al. 2000), suggesting that beliefs about health problems are at least as important in mental health as they are in physical health. One reason for the amount of variance being so small is that the outcome appraisal measures are very general and therefore likely to be influenced by variables other than those linked to health, such as relationships, housing, work etc.

The clinical significance of the variance in outcome appraisal accounted for by beliefs in both physical and mental health problems is unclear. Intervention studies are needed to test both the causal mechanism of the relationship between beliefs and outcome and the potential to change this relationship in a way that has a meaningful impact on peoples' lives. Petrie et al. (2002) reported the results of a Randomized Controlled Trial using a three-session early intervention to challenge illness perceptions following a myocardial infarction. They found a reduction in negative beliefs, and reduced delay in returning to work for the intervention group. Intervention studies specifically focused on challenging negative beliefs about mental health problems have not yet been reported.

The assertion that coping mediates the relationship between illness beliefs and outcome appraisal was not supported in this study. Beliefs had significant direct associations with outcome appraisal and coping generally accounted for little or no additional variance. However, firm conclusions cannot be drawn as there were considerable difficulties in accurately measuring coping. In this study, the reduction of specific strategies to categorical variables measuring positive and negative strategies is problematic in that fails to take into account the effectiveness of strategies for the individual, how consistently they are used, and the appropriateness of strategies to different settings. Finally, univariate associations between beliefs and coping suggest some degree of shared variance that is difficult to disentangle using these statistical methods (though tolerance statistics were checked to ensure that these associations were not causing multi-colinearity in the analyses).

Despite these problems, the finding that coping is not a mediator has potentially important implications of the mechanism underlying the association between beliefs and outcome. 
The finding is consistent with a number of physical health studies, which have failed to find strong evidence for the importance of coping (Moss-Morris et al. 1996; Heijmans, 1999; Steed et al. 1999). These studies suggest that rather than beliefs guiding attempts to cope, which in turn impact on outcome appraisal as the SRM suggests, beliefs about health problems may have a direct effect on the outcome. This is consistent with a more general cognitive models of psychosis as described by Morrison (2001), Birchwood et al. (2000) and Garety et al. (2001).

This study has several further limitations that need to be taken into account when interpreting the findings. The assessment of beliefs in this study does not include some potentially important dimensions. Beliefs about the causes of mental health problems and beliefs about personal responsibility and blame are assessed by the IPQS, but did not form internally consistent subscales and so were not used in this analysis (Lobban et al. in press). The important role of beliefs about specific treatments has also been highlighted in previous literature (Horne \& Weinman, 1995), but were not assessed.

The longitudinal analysis in this study showed little change over time. Future research may focus on longer time periods and on events that may be likely to be associated with change, such as interventions, or relapse.

Finally, there are important differences between physical and mental health problems that may limit the applicability of the SRM to psychosis. The SRM assumes that people hold models of illness in their heads that can be accessed by questioning. In psychosis, the nature of the disorder may impair the ability or the need to do this. In physical health problems there may be a desire to identify a disease entity that can be diagnosed and separated from the sense of self. In psychosis the distinction between self and illness is often more blurred and this may make the ability to create an illness model more difficult. The greater degree of stigma associated with psychosis may increase the impact of the social environment on the development and expression of beliefs in a way that is not currently addressed in current applications of the SRM.

Despite these limitations, the results have important clinical implications. They suggest that the current focus on symptom severity as a main outcome measure in clinical trials is perhaps unwarranted. Symptom severity accounted for some variance in outcome appraisal for individuals in this study, but perceived consequences, controllability and a sense of coherence were also very important. This highlights important opportunities for interventions that aim to challenge negative appraisals using well developed cognitive and behavioural therapies.

\section{ACKNOWLEDGEMENTS}

The authors thank Professor Chris Hatton and Professor Nicholas Tarrier for their assistance with rating the coping strategies and helpful comments on the final draft of the paper. Thanks also go to Kate Hancock and Zoe Rivers who carried out some of the assessment interviews. This work was supported by an MRC studentship bursary at the University of Manchester.

\section{DECLARATION OF INTEREST}

None.

\section{REFERENCES}

APA (1994). Diagnostic and Statistical Manual of Mental Disorder (4th edn). American Psychiatrical Association: Washington, DC.

Birchwood, M., Iqbal, Z., Chadwick, P. \& Trower, P. (2000). Cognitive approach to depression and suicidal thinking in psychosis. II. Testing the validity of a social ranking model. British Journal of Psychiatry 177, 522-528.

Birchwood, M., Mason, R., MacMillan, F. \& Healy, J. (1993). Depression, demoralization and control over psychotic illness a comparison of depressed and non-depressed patients with a chronic psychosis. Psychological Medicine 23, 387-395.

Connor, M. \& Norman, P. (1995). The role of social cognition in health behaviours. In Predicting Health Behaviour: Research and Practice with Social Cognition Models (ed. M. Connor and P. Norman), pp. 1-23. Oxford University Press: Buckingham, PA.

Edwards, R., Suresh, R., Lynch, S., Clarkson, P. \& Stanley, P. (2001). Illness perceptions and mood in chronic fatigue syndrome. Journal of Psychosomatic Research 50, 65-68.

Field, A. (2000). Discovering Statistics; Using SPSS for Windows. Sage: London.

Fortune, D. G., Richards, H., Griffiths, C. \& Main, C. (2002). Psychological stress, distress and disability in patients with psoriasis: consensus and variation in the contribution of illness perceptions, coping and alexithymia. British Journal of Health Psychology 41, 157-174.

Garety, P. A, Kuipers, E., Fowler, D., Freeman, D. \& Bebbington, P. E. (2001). A cognitive model of the positive symptoms of psychosis. Psychological Medicine 31, 189-195.

Heijmans, M. J. W. M. (1999). The role of patients' illness representations in coping and functioning with Addison's disease. British Journal of Health Psychology 4, 137-149.

Horne, R., Weinman, J. \& Hankins, M. (1998). The Beliefs about Medicines Questionnaire (BMQ): the development and evaluation 
of a new method for assessing the cognitive representation of medication. Psychology and Health 14, 1-24.

Kay, S. R., Opler, L. A. \& Lindenmayer, J. P. (1989). The positive and negative syndrome scale (PANSS) rationale and standardization. British Journal of Psychiatry 155 (Suppl. 7), 59-65.

Kinderman, P. \& Bentall, R. P. (1997). Causal attributions in paranoia and depression: internal, personal, and situational attributions for negative events. Journal of Abnormal Psychology 106, 341-345.

Leventhal, H., Nerenz, D. R. \& Steele, D. F. (1984). Illness representations and coping with health threats. In A Handbook of Psychology and Health (ed. A. Baum and J. Singer), pp. 219-252. Erlbaum: Hillsdale, NJ.

Lobban, F., Barrowclough, C. \& Jones, S. (in press). Assessing cognitive representations of mental health problems. I. The Illness Perception Questionnaire for Schizophrenia. British Journal of Clinical Psychology.

Morrison, A. P. (2001). The interpretation of intrusions of in psychosis: an integrative cognitive approach to hallucinations and delusions. Behavioural and Cognitive Psychotherapy 29, 257-277.

Moss-Morris, R., Petrie, K. J. \& Weinman, J. (1996). Functioning in chronic fatigue syndrome: do illness perceptions play a regulatory role? British Journal of Health Psychology 1, 15-25.

Moss-Morris, R., Weinman, J., Petrie, K., Horne, R., Cameron, L. D. \& Buick, D. (2001). The revised illness perception question. Psychology and Health 17, 1-16.

Oliver, J. P. J. (1991). The social care directive: development of a quality of life profile for use in community services for the mentally ill. Social Work and Social Sciences Review 3, 5-45.

Petrie, K. J., Cameron, L., Ellis, C. J., Buick, D. \& Weinman, J. (2002). Changing illness perceptions after myocardial infarction: an early intervention randomized controlled trial. Psychosomatic Medicine 64, 580-586.
Priebe, S., Huxley, P., Knight, S. \& Evans, S. (1999). Application and results of the Manchester Short Assessment of Quality of Life (MANSA). International Journal of Social Psychiatry 45 $7-12$

Purnine, D. M., Carey, K. B., Maisto, S. A. \& Carey, M. P. (2000) Assessing positive and negative symptoms in outpatients with schizophrenia and mood disorders. Journal of Nervous and Mental Disease 188, 653-661.

Rutter, C. L. \& Rutter, D. R. (2002). Illness representation, coping and outcome in irritable bowel syndrome (IBS). British Journal of Health Psychology 7, 377-391.

Scharloo, M. A., Kaptein, A. A., Weinman, J. A., Willems, L. N. A. \& Rooijmans, H. G. M. (2000). Physical and psychological correlates of functioning in patients with chronic obstructive pulmonary disease. Journal of Asthma 37, 17-29.

Steed, L., Newman, S. P. \& Hardman, S. M. C. (1999). An examination of the self regulation model in atrial fibrillation. British Journal of Health Psychology 4, 337-347.

Tarrier, N. (1987). An investigation of residual psychotic symptoms in discharged schizophrenic patients. British Journal of Clinical Psychology 26, 141-143.

Tarrier, N., Sharpe, L., Beckett, R., Harwood, S., Baker, A. \& Yusapoff, L. (1993). A trial of two cognitive behavioural methods of treating drug-resistant symptoms in schizophrenic outpatients. II. Treatment specific changes in coping and problem solving skills. Social Psychiatry and Psychiatry Epidemiology 28 $5-10$

Weinman, J., Petrie, K., Moss-Morris, R. \& Horne, R. (1996). The Illness Perception Questionnaire: a new method for assessing the cognitive representation of illness. Psychology and Health 11, 431-445.

Zigmond, A. S. \& Snaith, R. P. (1983). The hospital anxiety and depression scale. Acta Psychiatrica Scandinavica 67, 361-370. 


\section{APPENDIX}

Timeline acute/chronic

My mental health problems will last a short time (R).

My mental health problems are likely to be permanent rather than temporary.

My mental health problems will last for a long time.

My mental health problems will pass quickly (R).

I expect to have these mental health problems for the rest of my life.

My mental health problems will improve in time (R).

Timeline cyclical

Sometimes I have more symptoms than other times.

I have times when I am well and times when I am not so well.

Sometimes the symptoms of my mental health problems are worse than other times.

Some of my symptoms will be there all the time but others will come and go.

Consequences

My mental health problem is a serious condition.

My mental health problems do not have much effect on my life (R).

My mental health problems have financial consequences for me.

My mental health problems make it more difficult for me to do day to day things.

My mental health problems cause difficulties for those who are close to me.

I don't get on as well with our family since their mental health problems.

My mental health problems have messed up my social life.

My mental health problems mean that I am valued less by other people.

My mental health problems make working very difficult for me.

I have lost important relationships as a result of my mental health problems.

My mental health problems have had some positive effects on my life (R).

Personal control

There are some things that I can do to control my symptoms.

To some extent, what I do can determine whether my mental health problems get better or worse.

Nothing I do will affect my mental health problems (R).

My actions will have no effect on the outcome of my mental health problems (R).

Treatment control

There is little treatment available that can improve my mental health problems (R).

My treatment will be effective in managing my mental health problems.

The negative effects of my mental health problems can be prevented (avoided) by my treatment.

My treatment can control my mental health problems.

There is no treatment that can help with my condition $(\mathrm{R})$.

Illness coherence

I feel very puzzled by my mental health problems.

I don't have any understanding of my mental health problems at all.

I feel that I don't know anything about my mental health problems.

My mental health problems make no sense to me at all.

I have a clear picture or understanding of my mental health problems (R).

$(\mathrm{R})=$ reverse scored items 